\title{
Sensitivity of Four Sweetpotato Clones to Metribuzin Herbicide
}

\author{
Howard F. Harrison, Jr. ${ }^{1}$ and Philip D. Dukes ${ }^{2}$ \\ U.S. Vegetable Laboratory, Agricultural Research Service, U.S. Department \\ of Agriculture, 2875 Savannah Highway, Charleston, SC 29414-5334
}

Additional index words. Ipomoea batatas, herbicide tolerance

\begin{abstract}
Four sweetpotato [Ipomoea batatas (L.) Lam.] clones were evaluated for metribuzin tolerance in greenhouse and field experiments. W-262 exhibited metribuzin response similar to the highly tolerant clone Tinian (U.S.P.I. 153655). SC 1149-19 was highly sensitive to metribuzin, and the commercial cultivar Jewel was intermediate in tolerance. Due to its more desirable horticultural characteristics and higher yields, W-262 is superior to Tinian as a source of metribuzin tolerance in sweetpotato breeding. Chemical name used: 4-amino-6-(1,1-dimethylethyl)-3-(methylthio)-1,2,4-triazin-5(4H)-one (metribuzin).
\end{abstract}

The most serious limitation for weed control in sweetpotato in the United States is the lack of registered herbicides to control many weeds common in sweetpotato production areas. Currently, dimethyl-2,3,5,6-tetrachloro1,4-benzenedicarboxylate (DCPA) and 2-[(2 chlorophenyl)methyl]-4,4-dimethyl-3isoxazolidinone (clomazone) are the only registered herbicides with residual soil activity. Metribuzin has been evaluated for weed control in sweetpotatoes by several researchers (Lu-Chyuan and Borrero, 1982; Monaco et al., 1981; Monks et al., 1981). Metribuzin controls important sweetpotato weeds that are not controlled by DCPA or clomazone and allows flexibility in that it can be applied before or after planting (Weed Science Society of America, 1994). However, some sweetpotato cultivars are injured and their yields may be reduced by metribuzin. Sweetpotato clones vary in metribuzin tolerance, and the trait is highly heritable (Harrison et al., 1985, 1987; Motsenbocker and Monaco, 1993). The objective of this study was to assess metribuzin tolerance in an advanced sweetpotato breeding clone, W-262, by comparing its response to the responses of three clones of known metribuzin tolerance.

\section{Materials and Methods}

The metribuzin-tolerant sweetpotato clone, $\mathrm{W}-262$, was selected from a recurrent mass selection breeding program (Harrison et al., 1992). Two of the other clones in this study, Tinian and 'Jewel', were previously shown to be tolerant and intermediate in metribuzin response, respectively, in greenhouse and field experiments (Harrison et al., 1985). SC 114919 was included as a highly susceptible control.

Received for publication 28 Aug. 1995. Accepted for publication 15 Apr. 1996. The cost of publishing this paper was defrayed in part by the payment of page charges. Under postal regulations, this paper therefore must be hereby marked advertisement solely to indicate this fact.

${ }^{1}$ Research Agronomist.

${ }^{2}$ Research Plant Pathologist.
The techniques used in the greenhouse experiment were previously described (Harrison et al., 1985). Metribuzin was incorporated into a $50 \%$ (by volume) sand-peatvermiculite potting medium at $0,0.25,0.5$, $1.0,2.0$, and $4.0 \mathrm{mg} \cdot \mathrm{kg}^{-1}$. Sweetpotato vine cuttings were transplanted into pots containing treated potting medium and were grown for 5 weeks, after which injury was rated on a percentage scale $(0=$ no injury, $30=$ moderate foliar chlorosis, $70=$ severe foliar chlorosis and necrosis, and $100=$ dead plant) and shoot fresh weights were determined. The experiment was arranged in a completely random design with five replications and was repeated. Means and standard errors of the combined data set from two repetitions of the experiment were determined. Metribuzin concentrations required to cause $50 \%$ injury $\left(\mathrm{I}_{50}\right)$ or $50 \%$ reduction in shoot fresh weight $\left(\mathrm{GR}_{50}\right)$ were estimated for each clone using probit analysis after the method of Finney (1971).

Metribuzin tolerance of the four clones also was evaluated in field experiments in 1987, 1988, and 1990. The field experiment was arranged in a split-plot design with four replications. Main plots were $4 \times 6 \mathrm{~m}$, and main-plot treatments were metribuzin at 0 , $0.5,1.0$, and $2.0 \mathrm{~kg} \cdot \mathrm{ha}^{-1}$. Subplots were $6-\mathrm{m}$ long rows at a $1-\mathrm{m}$ spacing, and subplot treatments were sweetpotato clones.
Sweetpotatoes were grown under standard cultural practices as described by Harrison et al. (1985). Soil type in each year was a Yonges loamy sand (Aeric Paleaquults) with $<1 \%$ organic matter, and soil $\mathrm{pH}$ ranged from 6.3 to 6.8 . Sweetpotato vine cuttings were planted at a $30-\mathrm{cm}$ spacing on $50-\mathrm{cm}$ beds spaced $1 \mathrm{~m}$ apart. At $\approx 1$ week after transplanting, metribuzin was applied as a broadcast spray in $310 \mathrm{~L} \cdot \mathrm{ha}^{-1}$. Plots were cultivated and hoed to prevent weed interference. Five weeks after metribuzin application, sweetpotatoes were rated for visual injury using the scale described above. At 120 days after planting, sweetpotatoes were harvested and weighed. Injury ratings and total yields as a percentage of nontreated plot yields were subjected to analysis of variance following log transformation of the data to meet the assumption of the analysis for independence between means and variances. Cultivar means within a metribuzin rate were separated by protected least significant differences at $P \leq 0.05$. Differences between yields of metribuzin treatments and the yields of the nontreated controls were detected by the F ratios test at $P \leq 0.05$.

\section{Results and Discussion}

In the greenhouse dose-response study, W262 exhibited tolerance similar to Tinian, whereas SC 1149-19 was highly susceptible and 'Jewel' was intermediate in tolerance (Table 1). Estimated $I_{50}$ values were 0.4, 1.6, 3.2 , and $3.4 \mathrm{mg} \cdot \mathrm{kg}^{-1}$ of soil and $\mathrm{GR}_{50}$ values were $0.1,1.1,1.8$, and $1.9 \mathrm{mg} \cdot \mathrm{kg}^{-1}$ of soil for SC 1149-19, 'Jewel', W-262, and Tinian, respectively.

Differential metribuzin tolerance between sweetpotato clones also existed in the field experiments. SC 1149-19 exhibited $>40 \%$ injury at all metribuzin treatments (Tables 2 and 3 ), and its yields were reduced by all treatments except $0.5 \mathrm{~kg} \cdot \mathrm{ha}^{-1}$ in 1988 . 'Jewel' was intermediate in metribuzin tolerance; it exhibited $>40 \%$ injury with metribuzin at 1.0 and $2.0 \mathrm{~kg} \cdot \mathrm{ha}^{-1}$, except $1.0 \mathrm{~kg} \cdot \mathrm{ha}^{-1}$ in 1990 . 'Jewel' yields were reduced by 1.0 and $2.0 \mathrm{~kg} \cdot \mathrm{ha}^{-1}$, except $1.0 \mathrm{~kg} \cdot \mathrm{ha}^{-1}$ in 1988 . Tinian was injured $>40 \%$ only at $2.0 \mathrm{~kg} \cdot \mathrm{ha}^{-1}$ in 1987 , and its yields were not reduced by any treatment. W-262 exhibited metribuzin tolerance similar to that

Table 1. Leaf injury and shoot fresh weight of four sweetpotato clones in response to metribuzin incorporated into potting medium in the greenhouse. ${ }^{2}$

\begin{tabular}{lrcrr}
\hline $\begin{array}{l}\text { Metribuzin rate } \\
\left(\mathrm{mg} \cdot \mathrm{kg}^{-1} \text { of soil }\right)\end{array}$ & \multicolumn{4}{c}{ Sweetpotato clone } \\
\cline { 2 - 4 } & SC 1149-19 & Jewel & Tinian & W-262 \\
0.25 & $14 \pm 2$ & Crop injury $(\%)$ & $7 \pm 2$ \\
0.5 & $81 \pm 6$ & $11 \pm 1$ & $8 \pm 3$ & $11 \pm 2$ \\
1.0 & $98 \pm 1$ & $25 \pm 5$ & $10 \pm 5$ & $18 \pm 3$ \\
2.0 & $100 \pm 0$ & $39 \pm 6$ & $24 \pm 8$ & $29 \pm 3$ \\
4.0 & $100 \pm 0$ & $51 \pm 4$ & $37 \pm 10$ & $62 \pm 5$ \\
& & $75 \pm 3$ & $57 \pm 9$ & $124 \pm 12$ \\
0.25 & $104 \pm 8$ & Shoot weight $(\%$ of control) & & $90 \pm 9$ \\
0.5 & $12 \pm 5$ & $66 \pm 5$ & $114 \pm 15$ & $72 \pm 8$ \\
1.0 & $3 \pm 1$ & $54 \pm 4$ & $80 \pm 8$ & $49 \pm 4$ \\
2.0 & $2 \pm 1$ & $38 \pm 6$ & $32 \pm 6$ & $24 \pm 4$ \\
4.0 & $2 \pm 1$ & $16 \pm 1$ & $27 \pm 4$ & \\
\hline
\end{tabular}

${ }^{\mathrm{z}}$ Means \pm the standard error of the mean. 
Table 2. Visual injury ratings of four sweetpotato clones in response to metribuzin concentration in field tests in 1987,1988 , and 1990.

\begin{tabular}{|c|c|c|c|c|c|c|c|c|c|}
\hline \multirow{4}{*}{$\begin{array}{l}\text { Sweetpotato } \\
\text { clone }\end{array}$} & \multicolumn{9}{|c|}{ Injury rating $(\%)$} \\
\hline & \multicolumn{3}{|c|}{1987} & \multicolumn{3}{|c|}{1988} & \multicolumn{3}{|c|}{1990} \\
\hline & \multicolumn{9}{|c|}{ Metribuzin $\left(\mathrm{kg} \cdot \mathrm{ha}^{-1}\right)$} \\
\hline & 0.5 & 1.0 & 2.0 & 0.5 & 1.0 & 2.0 & 0.5 & 1.0 & 2.0 \\
\hline$\overline{\text { SC } 1149-19}$ & 64 & 96 & 100 & 54 & 92 & 94 & 44 & 63 & 75 \\
\hline Jewel & 22 & 58 & 81 & 24 & 41 & 54 & 21 & 35 & 43 \\
\hline Tinian & 6 & 18 & 58 & 11 & 18 & 21 & 7 & 11 & 17 \\
\hline $\mathrm{W}-262$ & 25 & 36 & 59 & 9 & 15 & 20 & 10 & 13 & 20 \\
\hline $\operatorname{LSD}_{0.05}{ }^{\mathrm{z}}$ & 24 & 13 & 20 & 16 & 10 & 12 & 10 & 15 & 17 \\
\hline
\end{tabular}

${ }^{2}$ LSD for comparing clone means within a column.

Table 3. Total storage root yields of four sweetpotato clones in response to metribuzin concentration in field tests in 1988, 1989, and 1990 .

\begin{tabular}{|c|c|c|c|c|c|c|c|c|c|}
\hline \multirow{4}{*}{$\begin{array}{l}\text { Sweetpotato } \\
\text { clone }\end{array}$} & \multicolumn{9}{|c|}{ Total yields (\% nontreated) } \\
\hline & \multicolumn{3}{|c|}{1987} & \multicolumn{3}{|c|}{1988} & \multicolumn{3}{|c|}{1990} \\
\hline & \multicolumn{9}{|c|}{ Metribuzin $\left(\mathrm{kg} \cdot \mathrm{ha}^{-1}\right)$} \\
\hline & 0.5 & 1.0 & 2.0 & 0.5 & 1.0 & 2.0 & 0.5 & 1.0 & 2.0 \\
\hline$\overline{\mathrm{SC}} 1149-19$ & $45^{*}$ & $0^{*}$ & $0^{*}$ & $85^{*}$ & $5^{*}$ & $4^{*}$ & $45^{*}$ & $6^{*}$ & $0^{*}$ \\
\hline Jewel & 57 & $8^{*}$ & $6^{*}$ & 90 & 64 & $27^{*}$ & 83 & $56^{*}$ & $18^{*}$ \\
\hline Tinian & 112 & 45 & 69 & 122 & 158 & 109 & 72 & 84 & 81 \\
\hline W-262 & 78 & 88 & $43^{*}$ & 95 & 87 & 69 & 99 & 90 & $65^{*}$ \\
\hline $\operatorname{LSD}_{0.05}{ }^{\mathrm{z}}$ & NS & 55 & 43 & NS & 45 & 39 & 29 & 39 & 26 \\
\hline
\end{tabular}

${ }_{\mathrm{Z}}^{\mathrm{LSD}}$ for comparing means within a column.

*Yields of treatments were significantly lower than control yields according to the F ratios test at $P \leq 0.05$. Nonsignifcant.

of Tinian. Injury ratings for the two clones differed only at $1.0 \mathrm{~kg} \cdot \mathrm{ha}^{-1}$ in $1987 . \mathrm{W}-262$ yields were reduced in comparison to the controls by metribuzin at $2.0 \mathrm{~kg} \cdot \mathrm{ha}^{-1}$ in 1987 and 1988.

Sweetpotato yields are typically variable in small plots, and variability might have been increased by the experimental design. Tinian is a particularly noncompetitive clone due to its sparse growth habit (for example, the average control shoot weights in the greenhouse experiment were $16.3,27.1,29.7$, and $29.4 \mathrm{~g}$ for Tinian, W-262, SC 1149-19, and 'Jewel', respectively), and the effect of metribuzin injury on the competitiveness of clones in adjacent rows may have increased Tinian yields in treated plots. Injury ratings for all clones were generally higher in 1987 than in 1988 or 1990 (Table 2), possibly due to droughty con- ditions during the 1987 growing season.

Metribuzin tolerance in Tinian and W-262 mally recommended rates $\left(0.3\right.$ to $0.6 \mathrm{~kg} \cdot \mathrm{ha}^{-1}$ on sandy soils) without causing severe injury or yield reduction. W-262 is an advanced sweetpotato clone that produces relatively high yields (Table 4 ) of high-quality roots and has many desirable horticultural characteristics and pest resistances (Harrison et al., 1992). Since metribuzin tolerance is highly heritable in sweetpotato (Harrison et al., 1987 ), this advanced metribuzin-tolerant clone should facilitate development of cultivars with increased metribuzin tolerance through the recurrent mass selection procedure. W-262 is superior to Tinian for use as a source of metribuzin tolerance in sweetpotato breeding due to its more desirable characteristics and is sufficient to allow metribuzin use at nor-
Table 4. Total yields of four sweetpotato clones in the nontreated control plots of field experiments during 3 years.

\begin{tabular}{lrrr}
\hline & \multicolumn{3}{c}{ Total yields $\left(\mathrm{Mg} \cdot \mathrm{ha}^{-1}\right)$} \\
\cline { 2 - 4 } Clone & 1987 & 1988 & 1990 \\
\hline SC 1149-19 & 15.9 & 13.3 & 27.2 \\
Jewel & 12.3 & 18.2 & 35.4 \\
Tinian & 2.2 & 1.5 & 9.4 \\
W-262 & 12.9 & 11.6 & 27.9 \\
LSD $_{0.05}{ }^{2}$ & 10.1 & 6.2 & 7.1 \\
\hline Z $^{2}$ &
\end{tabular}

${ }^{\mathrm{z}} \mathrm{LSD}$ for separating clone means within a year.

prolific flowering and seed production.

Limited quantities of W-262 shoot cuttings or seed roots may be obtained from H.F.H. by interested research and extension personnel.

\section{Literature Cited}

Finney, D.J. 1971. Probit analysis. Cambridge Press, London.

Harrison, Jr., H.F., A. Jones, and P.D. Dukes. 1985. Differential response of six sweet potato (Ipomoea batatas) cultivars to metribuzin. Weed Sci. 33:730-733.

Harrison, Jr., H.F., A. Jones, and P.D. Dukes. 1987. Heritability of metribuzin tolerance in sweet potato (Ipomoea batatas). Weed Sci. 33:715-719.

Harrison, Jr., H.F., P.D. Dukes, and A. Jones. 1992. Notice of release of W-262 sweetpotato breeding clone. USDA Germplasm Release, U.S. Dept. of Agr., Washington, D.C.

Lu-Chyuan, Lu and E. Acevedo Borrero. 1982. Herbicide evaluation for sweetpotatoes. J. Agr., Univ. Puerto Rico 4:254-260.

Monaco, T.J., R.I. Hunt, and R.J. Mills. 1981. Weed control investigations in horticultural crops. Res. Ser. 56. North Carolina State Univ.

Monks, D.W., D.L. Coffey, T.D. Cordrey, and W.J. McLaurin. 1981. Herbicide evaluation in sweetpotatoes. Proc. Southern Weed. Sci. Soc. 34:106.

Motsenbocker, C.E. and T.J. Monaco. 1993. Differential tolerance of sweetpotato clones to metribuzin. Weed Technol. 7:349-354.

Weed Science Society of America. 1994. Herbicide handbook. 7th ed. Weed Sci. Soc. Amer., Champaign, Ill. p. 200-203. 